
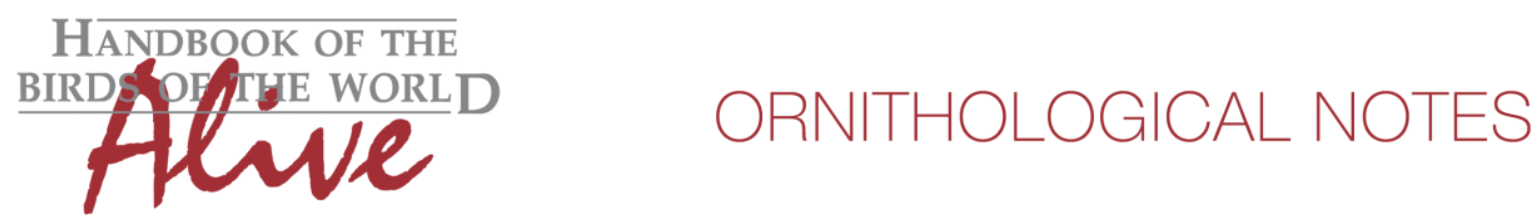

\title{
Notes on the vocalizations of McConnell's Flycatcher (Mionectes macconnelli)
}

Peter Boesman

In the following we briefly analyze and compare voice of the different races of McConnell's Flycatcher (Mionectes macconnelli). We also try to quantify the extent of any vocal differences using the criteria proposed by Tobias et al. (2010), as a support for taxonomic review. We have made use of sound recordings available on-line from Xeno Canto (XC) and Macaulay Library (ML).

Vocal differences between the 2 northern races (roraimae and macconnelli) have already been analyzed by Hilty \& Ascanio (2014), but this study did not look at all races and populations.

We are doing this analysis here:

\section{Guianan/Amazonian birds (M. m. macconnelli)}

Song at lek is a variable series of harsh buzzy notes "rree..rree..rree..rree.." (Fig. 1). Call is a peculiar nasal descending call followed by a nasal trill "kyaw..jujujujujuj".

song $\mathrm{N}$ of Amazon (including Amapa):

$\begin{array}{ll}\text { max. note length } & 0.17-0.22 \mathrm{~s} \\ \text { min. pause. } & 0.09-0.15 \mathrm{~s} \\ \text { lowest freq. } & 1300-1530 \mathrm{~Hz} \\ \text { Note shape: } & \text { completely buzzy, at bottom frequencies nicely overslurred }\end{array}$

song S of Amazon river:

$\begin{array}{ll}\text { max. note length } & 0.23-0.31 \mathrm{~s} \\ \text { min. pause. } & 0.09-0.13 \mathrm{~s} \\ \text { lowest freq. } & 1380-1470 \mathrm{~Hz} \\ \text { Note shape: } & \text { Every note is in fact a composite of some 3-8 well-articulated notes, bottom } \\ & \text { frequencies are slightly rising }\end{array}$

\section{Tepui birds (M. m. roraimae)}

Song sounds like a jumbled chatter, but when closely looking it is quite similar in structure to macconnelli $\mathrm{S}$ of river Amazon but less orderly and especially in the beginning almost without clear pauses

max. note length min. pause. lowest freq. note shape:
$0.24-0.26 \mathrm{~s}$

Os at start about 0.10 s towards end $1000-1100 \mathrm{~Hz}$

Every note is a composite of several notes, but much less orderly than in macconnelli $\mathrm{S}$ of Amazon, bottom frequencies irregular 


\section{HANDBOOK OF THE BIRDSPF THE WORLD PNe}

\section{ORNITHOLOGICAL NOTES}

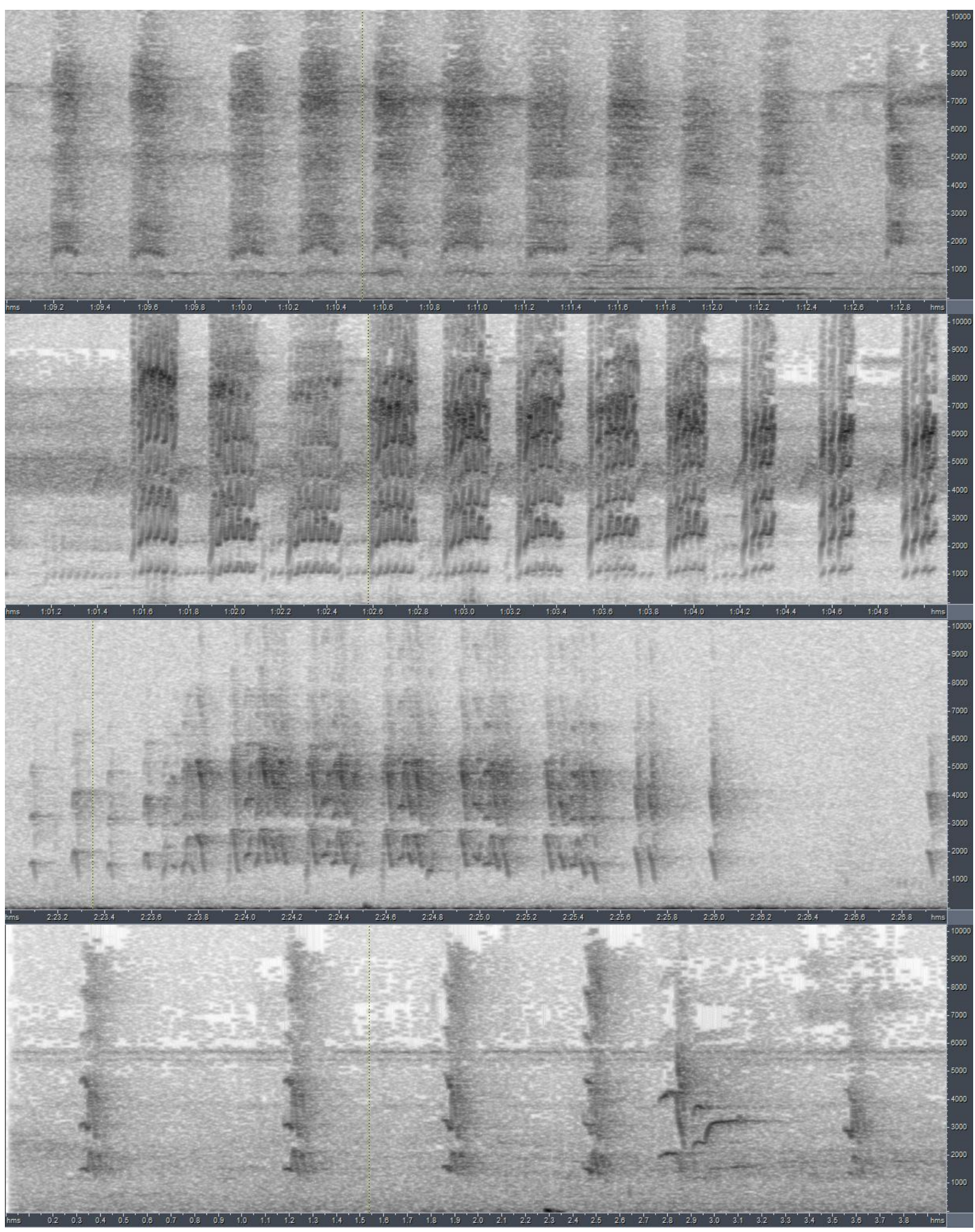

Figure 1: from top to bottom: typical song of macconnelli $\mathrm{N}$ of Amazon, macconnelli $\mathrm{S}$ of Amazon, roraimae and peruanus 

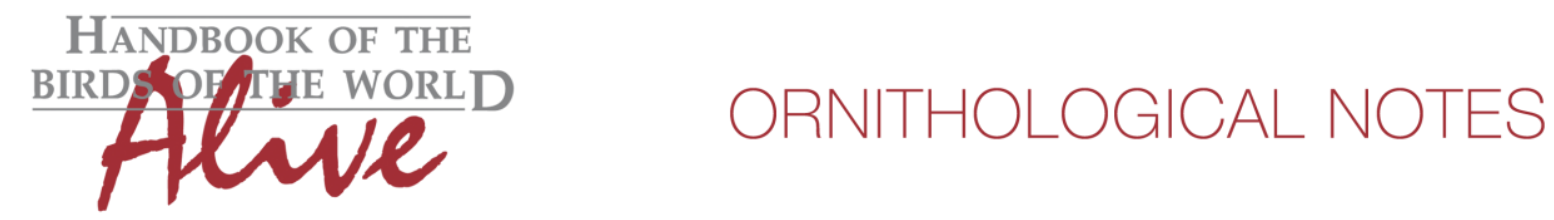

Andean foothill birds (M. m. peruanus and part of M. m. macconnelli ??)

Song is a series of well-spaced short nasal burry notes, occasionally interspersed with a completely different querulous note (described in Schulenberg et al. as tequila? or teeola?) . This song with a two note structure reminds somewhat Ochre-bellied Flycatcher $M$. oleaginus (as a matter of fact, 2 recordings from SE Peru in ML said to be macconnelli are in fact oleaginus)

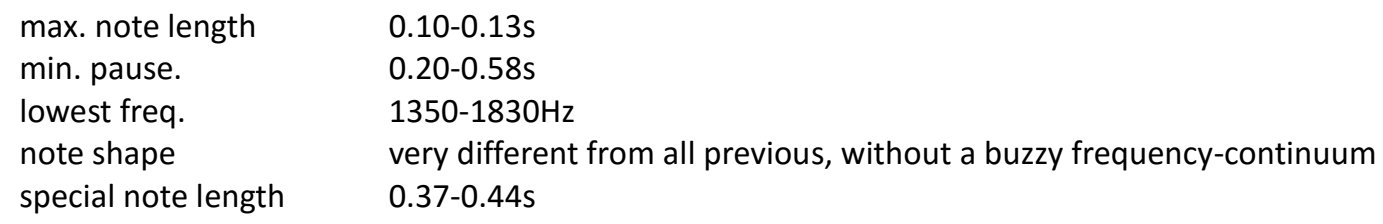

\section{Conclusion:}

There are clearly 4 vocal groups.

Song of macconnelli of the Guianan/Amazonian region is readily identified as pertaining either to birds $\mathrm{N}$ or $\mathrm{S}$ of the Amazon, because of the composite vs buzzy note structure (score 1-2), and the longer max. note length in the south (score 1-2). When applying Tobias criteria, the total score for vocal difference between these 2 populations would be about 3 .

roraimae is most similar to macconnelli $\mathrm{S}$ of Amazon, but is readily identified by the more chaotic delivery of composite notes with no clear pause at first (score 2-3). Notes also reach lower frequencies (score 2). Total score about 4.

Song of Andean foothill birds (peruanus) is very different in structure, and as such differs in many basic parameters: different note lengths (score 2-3), a two-note structure (score 2)and much larger pauses (score 3). Total score about 5-6.

(There is however some reservation, due to one deviating recording, closer to macconnelli) It seems important to further investigate this, as this taxon having structurally the most deviating song, seems a good candidate for elevation to species status.

This note was finalized on 3rd July 2015, using sound recordings available on-line at that moment. We would like to thank in particular the sound recordists who placed their recordings for this species on XC and ML: Bennett Hennessey, Sebastian Herzog, Steven Hilty, Alex Lees, Gabriel Leite, Curtis Marantz, Jeremy Minns, Brian O'Shea, Otte Ottema, Alexandre Renaudier, Mark Robbins 


\section{References}

Hilty, S., Ascanio D. (2014). McConnell's Flycatcher Mionectes macconnelli is more than one species. Bull BOC 134(4): 270-279.

Schulenberg T.S., Stotz, D.F., Lane, D.F., O'Neill, J.P. and Parker, T.A. (2007). Birds of Peru. Princeton University Press. Princeton and Oxford.

Tobias, J.A., Seddon, N., Spottiswoode, C.N., Pilgrim, J.D., Fishpool, L.D.C. \& Collar, N.J. (2010). Quantitative criteria for species delimitation. Ibis 152(4): 724-746.

\section{Recommended citation}

Boesman, P. (2016). Notes on the vocalizations of McConnell's Flycatcher (Mionectes macconnelli). HBW Alive Ornithological Note 118. In: Handbook of the Birds of the World Alive. Lynx Edicions, Barcelona. (retrieved from http://www.hbw.com/node/932023 on 4 August 2016). 